\title{
Obsessive Compulsive Disorder (OCD): The Ritual Moment of Social Death.
}

This article is an ethnographic study of individuals self-diagnosed with Obsessive Compulsive Disorder in Liverpool, UK. While much research on OCD has concentrated upon superstitious belief, psychosis and anxiety provoking disorder, the article focuses upon the relationship between the familiar and the strange in ordinary life, the 'disquieting familiar', captured by the Freudian idea of the uncanny. Investigated is how misfortune, as opposed to psychological neurosis, becomes attached to mass-produced objects and routine - kitchen taps obsessively touched, bank cards compulsively checked - and repetitive ritual enacted by individuals is revealing of the effort to prevent the emergence of apprehension concealed in everyday habitus and physical, concrete activity.

Obsessive Compulsive Disorder today is the fourth most common mental disorder in the UK after depression, alcohol/substance misuse, and social phobia. While the severity of OCD differs markedly from one person to another, its prevalence suggests that the visible grounds of daily experience are often invisible. The Annals of General Psychiatry illustrates how the treatment of the so-called 'doubting disease' largely ignores epidemiological explanations of mental illness as culturally bound, with diagnosis being caught between changing biomedical and neuropsychiatric accounts of disorder and maladaptation (Black 2008). Fornaro (2009), looking at the history of OCD, cites a passage from the Malleus Maleficarum, the 15thcentury compendium of witchcraft, which describes a priest brought to Rome for exorcism: 'when he passed any church... the devil made him thrust his tongue... when he tried ..engage in prayer, [the devil] attacked him ... violently' (2009:9). Later, with a biomedical shift in psychiatry, culpability shifted to an understanding of OCD as an abnormal functioning of the orbital frontal cortex (Lochner 2003). OCD UK lists four main types of OCD: checking, hoarding, contamination and rumination/intrusive thoughts. In the instance of checking, the repetitive use of objects is designed to prevent a disturbing event. Engaging with LevyBruhl's (1926 [1965]) idea of sympathetic magic, where the actor engages with the main laws of sympathetic magic: contagion (once in contact, always in contact) and similarity (the image equals the object), OCD UK's website describes the compulsion to enact ritual to prevent obsessional thoughts:

For someone with OCD, their logical mind always remains functioning.... Most people with OCD know that their thoughts and behaviour are irrational and senseless, but feel completely incapable of stopping them, often from fear that not completing a particular behaviour will cause harm to a loved one...People with OCD ... believe the only way to relieve the anxiety 
...is to perform compulsive behaviours... repetitive physical behaviours ... mental thought rituals that are performed over and over again... to relieve the anxiety caused by the obsessional thoughts

Commonly in the OCD literature, obsessions are recorded when a previously neutral object is associated with a stimulus that produces fear, even though it played no causative role (Black 2008). In examining repetitive ritual, common objects listed by OCD Charities as preventing what are termed 'bad' thoughts include: gas or electric oven stoves, water taps, door locks, house alarms, windows, appliances, house lights, car doors, wallets or purses, checking illnesses and symptoms online, rereading words or lines in a book over and over again. As a result, the silence of internal compulsive behaviours will take hours and often prevent individuals from interacting with anyone else during this time.

Conducting ethnographic fieldwork in South Liverpool in 2016, initially in the homes of four middle-aged women self-diagnosed with long-term OCD, how is misfortune and the materiality of objects mutually localised? Analysing the 'critical' event, amid a presence of fear in everyday life in India, Das (2007:9) writes how the perspective of the subject comes to establish a horizon along which objects and events are stitched together, torn and strewn within frayed everyday life (Das 2007:13). Exploring the private world of OCD sufferers, mass-produced objects (such as a juice carton, as will be illustrated) will wreak havoc amid very complicated material entanglements. Indeed, the habitual nature of the everyday is anything of the sort and ordinary life requires incredible effort. Unlike those who participate in superstitious ritual where the focus is upon a lucky fetish, a rabbit's foot or lucky coat, those self-diagnosed with OCD put their bodies in the direction of all sorts of things: checking and touching a can full of B\&Q weed killer, a sink plug, a kitchen dish cloth, bathroom grouting, Colgate toothpaste, the hum of a boiler, sofa cushions plumped incorrectly - one woman could not walk through John Lewis' cushion and bedroom sheet collection without touching every item - they contrive to open 'strange' pathways that must be closed down. Interlocutors, as the imaginary is localized within the physical and automated world (Marguiles 1996; Das 2007), ritualistically play with the idea of a wellspring of potential, the 'automatically' inescapable ordeal that is ever present and assumes an immediacy if compulsive routines are not maintained.

For Liza ${ }^{1}$, just keeping an orange-juice carton (always the same Tesco brand) in her fridge brought her a degree of tranquillity, but equally was a reminder of two events she deliberated

\footnotetext{
${ }^{1}$ All names have been changed to preserve anonymity
} 
about incessantly: losing her job and terminal ovarian cancer. The carton was her point of focus and suffocated her, but she felt compelled to glance at it for hours at a time. It was both reassuring and anxiety-provoking. It sucked up her uncertainty as the carton assumed a life of its own and "bent" around her despair to "stop stuff coming true." At other times, it alienated and distressed her: she could not touch her Toni \& Guy shampoo bottle or drink a cup of Tetley tea beforehand if she had not "noticed" the juice carton. Once, when she moved it, she did not wash her hair for a week in case her "belly ache turned out to be ovarian pain". On other occasions, she released her car handbrake seventeen times to ward off cancer. One day, she was late for work as, every time she glanced out of 'the corner of her eye' at the carton, she was "forced" to look at it again at a different angle or up close because otherwise her 'worst nightmare might happen'. She wanted to throw it away but worried as to the effects of this on her "undiagnosed" tumour which might burst forth at any second: whether not engaging with the carton would set off an instinctive chain of symptoms which, once in motion, could not be blocked. Her mind became full of the same incessant thoughts - of dying, her partner becoming ill with cancer, her daughter losing her job, and also of developing symptoms that led to a cancer diagnosis. So she sat looking at the carton as a reassuring reminder of "preventing everything hanging by one thread", while also feeling the disturbing sense of being hamstrung by the orange-juice carton in a life where little, she despaired, changed for the better. The orange-juice carton, as a ritual repository, stamped its shape upon settling and unsettling forces without fail.

Joanne, a school receptionist, felt a deep unease and "always have... like my anxiety about fire igniting out of the blue." Her narrative centred upon an electric hob in her kitchen which she repeatedly touched. It held an almost epistemic stability for Joanne, a centre of certainty and familiarity. Yet, on several occasions, her fingers were raw from scrapping the cooking dials over and over again as she sought to prevent a fire that she imagined to be so fierce that the hob dial could not cope with this happening. The fear nagged her not only that her own house might burn down, but that her mother's dishwasher might catch fire; that she might have badly wired electrics; that her computer would catch fire; her mother might be unaware that she had a potential fire hazard in her kitchen; the smoke alarm would not work. Sometimes she forgot this anxiety-provoking thought only to remember it again and look up the danger of faulty wiring on the internet. She once had been on holiday in Wales only to spill red nail varnish on the carpet of her rental accommodation. In this instance she became anxious that the spillage was a sign she needed to touch the electric hob again. So she cut her 
holiday short and drove home, berating herself on the entire journey, stopping every so often to listen to the car engine. The number varied - sometimes it was a group of three listens three times, at other moments this had to be reset because the ordering of something she could not quite put her finger on was out of sync and the journey took a day. Things conspired to unravel her holiday, ruined by the thought that an electrical fire might occur. "Tiny smoothing of the hob and life stays the same. No drama" she said. A concentration on familiar things decides what is to become a gnawing anxiety and what goes unnoticed and unnoticeable. Some days, unless she tapped not only the hob but also her bedroom curtains, shower nozzle, living-room door-frame and lounge window sill a particular number of times over and over again, she could not leave her house. She told me: “...though once I was stuck in a bathroom at the Trafford Centre touching sinks, then licking the cubicle door. I was worried that the hob might switch on the very moment I stopped... and ... get to the end of my road and see fire engines. A security guard asked if I needed help."

Objects feed unpredictable potential into ritual practice. A boiler set at the wrong temperature may emotionally tear away at an individual, its temperature set too hot may cause an unravelling of an unbearable thought. A clock must be daily stopped from ticking and wound backwards several times, or overwound if the subject is to leave their home. A washing machine habitually demands that it must be used on only one spin, 30 degrees in order that a computer virus does not destroy valuable documents. Joanne had been told, she repeated, on countless occasions by her partner that she was psychotic and that her "habits" could not control the world. Her logic, he said, was wrong and irrational. Of course, as Joanne's partner's comments illustrate, as linear uniform causality is difficult to think beyond, fetishization becomes a tool to undermine and make primitive the notion of animism. Yet, following from Evans Pritchard's seminal work Witchcraft, Oracle and Magic among the Azande (1937) in the Sudan, misfortune becomes less about causality and more about reciprocity. Commit a moral transgression and a misfortune, such as a frightening thunderstorm or a bout of serious illness, will happen to you and your group. Elsewhere, I have described how the movement of American mass-produced commodities into the spiritual realm is an intricate tenet of popular Ghanaian occult discourses in New York City (Parish 2017). In order to shield clients from witchcraft caused by greedy, envious female relatives in the matrilineage, Akan shrine spirits (abosom) from the Central and Western Regions of Ghana transform objects and subjects as 'esoteric registers are shifted to material registers and back again as presences pour into objects' (Johnson 2014:3). West African 
occult discourses slide between awkward scales encompassing a moral metanarrative of suffering, alienation and inequality, but also of personal conflict and dispute. Witchcraft narratives are representative of fissure, breakdown and shattering happenings - illness, car accidents, relationship breakdowns, addictions and bankruptcy. Events need to be classified as catastrophically tragic in order to fall under the rubric of witchcraft. Whilst Joanne and Lisa invest a lot of time and effort in a concerted attempt to stabilize the personal wounds trafficked by minor, impersonal objects, this is a state of disorder whose effects lie hidden and kept a lid on. Joanne and Lisa put incredible effort into normalising the 'unfamiliar' everyday. Each tries to ensure that ordinary life continues, unabated, in spite of the regular rhythms of the disturbing (Das 2007). For the same mundane object, as Joanne illustrates, may be materially ambiguous, both familiar and anxiety-provoking or, in her words, "like Jekyll and Hyde. Like really there solid in front of me and really, really like weird and spooky. Like brilliant and sometimes like really a monster."

One useful way of looking at the so-called 'technological imagination' (Sneath 2009) possessed by Joanne and Lisa is through Freud's world of the uncanny (Geschiere 2013). For Freud (1915 [1965]), the uncanny is most felt in the physical mechanical world of automation where it is a mixture of both the strange and the known that cannot be resolved (Royal 2003). The uncanny, understood as the emergence of a set of tangible and elusive effects, can be used to explore the conditions under which the strange comes about (Parish 2017). For the purposes of this research, it is important to understand the uncanny as 'the incongruous in the familiar.' Everyday objects provoke a sense of hope and despair as 'homeliness' has the power to turn so that what was once known and accustomed becomes a seed of turmoil. Indeed, the seemingly very ordinary dynamics of mechanical immobility may amplify in daily life as seemingly inanimate, mass-produced objects, express themselves against the subject to bring about the disquieting familiar (Marguiles 1996:90).

The rapid unsettling feelings felt by Liz, a teacher, are played out repetitively in daily life, with minute attention paid to detail. For Liz, her repetitive routines allow her to focus and make the strange familiar again. Her anxiety often returns to a roof that was once leaking twenty years ago and which might need expensive repairs again if piles of paper files in her house are moved. Her OCD narrative encompasses insurance companies and neighbours whose fault it was that the roof leaked in the first place; an insurance company that now cannot be changed, even though it is more expensive than others, because of the one time it paid out 18 years ago; piles of papers that cannot be moved in case of an insurance claim that 
will not be settled; piles of insurance documents that cannot be touched lest they precipitate the very event to be avoided; more and more insurance being taken out on a boiler, water pipes, fridge and washing machine; a life bound by the repetition of ordinary objects that prevent an insurance company from taking the wrong turn. Liz spoke of how "I cannot make you understand... how awful this is for me... how like massive this is... and so... very tiring. Rituals make it go away... always here on my mind... I live obsessing over a bloody roof. I am pathetic."

OCD sufferers, such as Joanne and Liza, refuse to accept that the disturbing is anything but a perpetual existence, simultaneously hidden and exposed by the rhythms of habitus and mechanical technology. The relations between different objects - a hammer, a tin of dog food, a lamp, a memory stick, a television screen, a page of a kindle book read repetitively make up pieces of a material circuit (Larkin 2008). Motionless objects are therefore nothing of the sort as the same object may inspire a spectrum of transformative effects. Compulsive rituals pattern, at least for some subjects, a turning point for those involved, marking a strange ordinariness or an awkward relationship between objects. They enable the projection of one's own intimate, catastrophic thoughts, while also allowing everyday life to continue. Jo, an office worker, described a serene sense of calmness when, in her words, things "feel right", when a pen on her desk was at a precise angle to her mouse mat and no longer brought forth a fear of infertility and a life without children. Her everyday life is read through this make-up of leaving her office and smiling in the mirror twice and then walking back to move the pen. Every other weekday she would do this hundreds of times in case "I never smile again." It is this fear which pulls the interlocutor back to examine the ordinary repetitively, often using commonplace objects, and recognise that there has to be attention paid to the familiar in order to think about the worst so that the experience of ordinary life may go on as it was before.

\section{References}

Black, Donald.W. 2008. 'Anxiety and the spectrum of obsessive-compulsive disorder. Introduction.' CNS Spectr.13 (9 Suppl 14):4-5

Das, Verda. 2007. Life and Words. Violence and the Descent into the Ordinary. California: University of California Press

Evans-Pritchard, EE. 1937. Witchcraft, Oracles and Magic among the Azande. London: Clarendon Books 
Fornaro, Michele. 2009. 'Obsessive-compulsive disorder and related disorders: a comprehensive survey'. Annals of General Psychiatry 8:13

Freud, Sigmund. 1915 (1965). The Uncanny. London: Penguin

Geschiere, Peter. 2013. Witchcraft, Intimacy and Trust. Africa in Comparison. Chicago:

University of Chicago Press

Harvey, Penny, 2015. 'Materials' in: Appel, Hannah, and, Nikhil and Gupta, Akhil. 'The

Infrastructure Toolbox.' Theorizing the Contemporary, Cultural Anthropology website, September 24, 2015

Johnson, Christopher Paul. 2014. Spirited Things. The Work of Possession in Afro-Atlantic

Religion. Chicago: University of Chicago Press

Larkin, Brian. 2008. Signal and Noise. Media, Infrastructure and Urban Culture in Nigeria.

Durham: Duke University Press

Levy-Bruhl, Lucian. 1926 (1965). How Natives Think. London: Martino Fine Books

Lochner, Christine and Stein, Dan..J. 2003. 'Heterogeneity of Obsessive Compulsive

Disorder. A Literature Review.' Harvard Review Psychiatry 11(3):113-32

Marguiles, Ivone. 1996. Nothing Happens. Chantel Akerman's Hyperrealist Everyday. Duke University Press

Parish, Jane 'Uncanny Objects and the Fear of the Familiar. Hiding from Akan witches in

New York City'. Journal of Material Culture, $31^{\text {st }}$ August 2017 DOI:

$10.1177 / 1359183517725100$

OCD UK www.ocduk.org

Royle, Nicholas. 2003. The Uncanny. Manchester: Manchester University Press

Sneath, David, Martin Holbraad \& Morten Axel Pedersen. 2009. 'Technologies of the Imagination: An Introduction.' Ethnos Vol 71, 1:5-30 